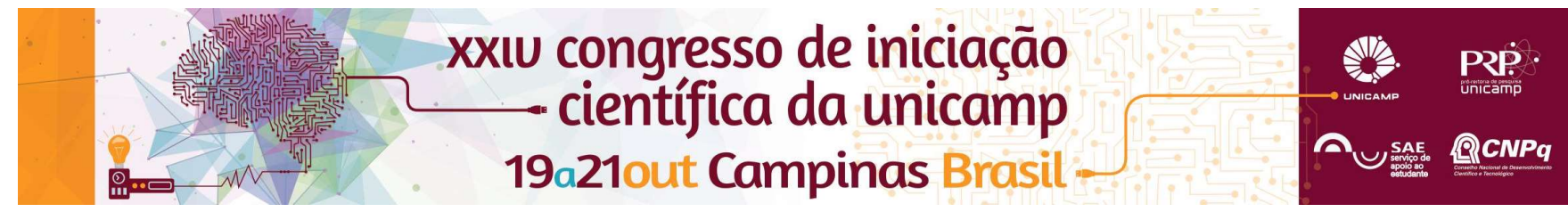

\title{
CORRELAÇÃO ENTRE VELOCIDADE DE PROPAGAÇÃO DE ONDAS DE ULTRASSOM E RESISTÊNCIA A PERFURAÇÃO
}

\author{
Luiz E. M. Libanio*, Alex J. Trinca, Raquel Gonçalves, Mariana dos R. Guerra.
}

\begin{abstract}
Resumo
A tomografia ultrassônica e a resistência a perfuração são importantes ferramentas para subsidiar a tomada de decisão a respeito da manutenção ou da retirada de uma árvore. As duas tecnologias têm sido vistas como complementares, mas ainda há muitas dúvidas a respeito do significado da imagem tomográfica, da amplitude resultante do ensaio de resistência a perfuração e de como utilizar a associação na melhoria do diagnóstico. Essa pesquisa teve como objetivo analisar a associação da tomografia ultrassônica com a resistência à perfuração. Os resultados preliminares permitem evidenciar que a associação das técnicas permite melhorar a precisão do diagnóstico.
\end{abstract}

\section{Palavras-chave:}

Análise de risco de queda, arborização urbana, tomografia ultrassônica, resistência à perfuração.

\section{Introdução}

Encontra-se em desenvolvimento, no Laboratório de Ensaios Não Destrutivos (LabEND) da FEAGRI, projeto que visa desenvolver metodologia e equipamento de tomografia ultrassônica com tecnologia nacional. No escopo deste projeto estão estudos que visam o melhor entendimento dos resultados apresentados por equipamentos de inspeção, quer de forma isolada quanto associadas. No caso da propagação de ondas o equipamento utilizado é o Ultrassom, desenvolvido no grupo de pesquisa e, no caso da resistência à perfuração, o Resistógrafo. $O$ objetivo desta pesquisa de iniciação cientifica foi avaliar a correlação entre parâmetros acústicos (velocidade de propagação das ondas de ultrassom) e a resistência a perfuração. $O$ delineamento experimental foi composto de discos retirados de troncos de árvores com diferentes tipos e graus de deterioração, suprimidas do campus da Unicamp.

\section{Resultados e Discussão}

Do resultado dos ensaios foram geradas imagens tomográficas bem como gráficos de resistência à perfuração, os quais foram analisados de forma isolada e conjunta. Neste resumo apresenta-se o estudo de caso com o disco da espécie Copaifera sp (Copaiba) - Figura 1 , que apresentava deterioração severa.

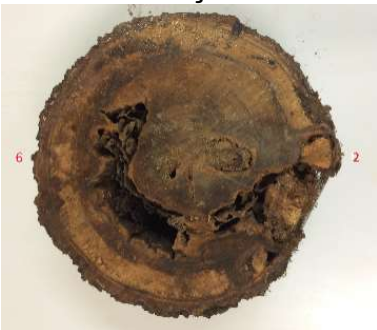

Figura 1: Fotografia do disco de Copaifera sp (Copaiba)

A imagem gerada pela tomografia ultrassônica (Figura 2) mostra zonas em cinza (madeira em bom estado) e zonas em preto (madeira com deterioração), retratando que grande parte do disco está deteriorado (em preto). O intervalo de velocidade das zonas pretas são, para especialistas, indicativo do nível de deterioração, mas não é possível garantir que se trata de um oco ou de uma degradação severa. $O$ resistógrafo apresenta um gráfico de amplitude que representa a resistência da madeira à perfuração (Figura 2). Zonas com amplitudes mais baixas indicam menor resistência a perfuração e zonas com amplitude zero representam ocos. Assim, isoladamente, também representa adequadamente a condição de deterioração da madeira. No entanto, além de ser um ensaio muito pontual (somente na direção da agula), o significado da amplitude em relação ao nível de deterioração só é evidente para o caso do oco (amplitude zero). Assim, a associação dos dois métodos (Figura 2) permite visualizar, com maior clareza, a condição real do disco, destacando das zonas em preto os locais onde a madeira está ocada e onde há redução da rigidez, mas não um oco.

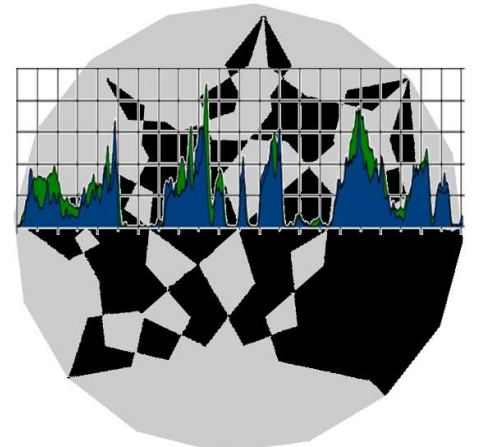

Figura 2: Imagem de tomografia ultrassônica e gráfico de amplitude de resistência a perfuração.

Zonas com velocidades indicativas de deterioração em preto.

\section{Conclusão}

As análises ainda estão em andamento, porém, é possivel concluir que a associação dos métodos fornece subsídios para a elaboração de laudos mais seguros a respeito da supressão ou da manutenção de um indivíduo arbóreo.

\section{Agradecimentos}

À FAPESP (Proc. 2015/05692-3) e à Prefeitura do Campus, Diretoria de meio ambiente, pelo apoio financeiro e de material para a pesquisa e ao CNPq e CAPES pelas bolsas de Iniciação Científica e Mestrado. 